\title{
PENGARUH DANA PIHAK KETIGA, CAR, NPL, BI RATE, INFLASI DAN NILAI TUKAR MATA UANG TERHADAP PROFITABILITAS BANK UMUM PERSERO TAHUN 2007-2018
}

\section{Gugum Mukdas Sudarjah, Sidik Priadana, Reza Anugrah Pratama}

Universitas Pasundan (UNPAS) Bandung Jawa Barat, Indonesia

Email: gugummukdassudarjah@unpas.ac.id, sidik.priadana.dim@unpas.ac.id dan anugrahpratamareza@gmail.com

\section{Abstract}

The Bank is a business entity that in its business activities raises funds from the community and its mines in the form of credit. As for the banking structure in Indonesia, it consists of commercial banks and BPR. Adaris main commercial banks and BPR what no one is in a way of depositing giro and can not also be cross-payment, can not be in-activities in foreign exchange and limited stage operations. This research is an expectation to know the Macroeconomics and Internal Performance performance of Bank Persero and BPD for the period 20072018 and to know how the influence of Third Party Funds, CAR, NPL, BI Rate, Inflation and Exchange Rate on the Profitability of Bank Persero and BPD. The sample in this study is Persero Commercial Bank. This study uses descriptive and verificative methods. Data analysis then which way of analysis data panel regression. The results of the study point that Simultaneously has 3 variables of positive, but uneven relationships, namely CAR, DPK, and BI Rate. As for npl variables and exchange rates have a good relationship and exchange rate results. When viewed from the coefficient value of each variable, then the VARIABLE NPL and Exchange Rate have a considerable influence on the performance of profitability.

Keywords: ROA; CAR; DPK; NPL; BI Rate; exchange rate

\section{Abstrak}

Bank merupakan badan usaha yang dalam kegiatan bisnisnya menghimpun dana dari masyarakat dan menyalurkannya dalam bentuk kredit. Sedangkan untuk struktur perbankan di Indonesia, terdiri atas bank umum dan BPR. Perbedaan utama bank umum dan BPR adalah tidak dapat menerima simpanan berupa giro dan tidak dapat turut serta dalam lalu lintas pembayaran, tidak dapat melakukan kegiatan bisnis dalam valas dan jangkauan kegiatan operasional yang terbatas. Penelitian ini bertujuan untuk mengetahui kondisi Ekonomi Makro dan Perkembangan kinerja internal Bank Persero dan BPD periode 2007-2018 serta untuk mengetahui bagaimana pengaruh Dana Pihak Ketiga, CAR, NPL, BI Rate, Inflasi dan Nilai tukar terhadap Profitabilitas Bank Persero dan BPD. Sampel dalam penelitian ini yaitu Bank Umum Persero. Penelitian ini menggunakan metode deskriptif dan verifikatif. Metode analisis data yang digunakan adalah analisis regresi data panel. Hasil penelitian menunjukan bahwa Secara simultan terdapat 3 variabel memiliki hubungan positif, namun tidak signifikan, yakni CAR, DPK, dan BI Rate.

$\begin{array}{ll}\text { How to cite: } & \text { Mukdas Sudarjah, Gugum, Sidik Priadana dan Reza Anugrah Pratama (2021) Pengaruh Dana Pihak } \\ & \text { Ketiga, Car, Npl, Bi Rate, Inflasi Dan Nilai Tukar Mata Uang Terhadap Profitabilitas Bank Umum } \\ & \text { Persero Tahun 2007-2018, (3)6. https://doi.org/10.36418/syntax-idea.v3i6.1246 } \\ \text { E-ISSN: } & \text { 2684-883X } \\ \text { Published by: } & \text { Ridwan Institute }\end{array}$


Sedangkan untuk variabel NPL dan Nilai Tukar memiliki hubungan negatif dan menunjukan hasil yang signifikan. Jika dilihat dari nilai koefisien dari setiap variabel, maka variabel NPL dan Nilai Tukar memberikan pengaruh yang cukup besar terhadap kinerja profitabilitas.

Kata Kunci: ROA; CAR; DPK; NPL; BI Rate; nilai tukar

\section{Pendahuluan}

Undang-undang Nomor 10 Tahun 1998 tentang perbankan, menyatakan bahwa Bank merupakan badan usaha yang dalam kegiatan bisnisnya menghimpun dana dari masyarakat dan menyalurkannya dalam bentuk kredit. Sedangkan untuk struktur perbankan di Indonesia, terdiri atas bank umum dan BPR. Perbedaan utama bank umum dan BPR adalah tidak dapat menerima simpanan berupa giro dan tidak dapat turut serta dalam lalu lintas pembayaran, tidak dapat melakukan kegiatan bisnis dalam valas dan jangkauan kegiatan operasional yang terbatas. Pasal 21 dalam Undang-undang Perbankan menyatakan bahwa terdapat dua kategori bentuk hukum perbankan di Indonesia, yakni bank umum dan bank perkereditan rakyat. Untuk bank umum memiliki bentuk hukum; (1) persersoran terbatas; (2) koperasi; (3) perusahaan daerah.

Ukuran bank merupakan indikator dalam mengukur seberapa besar dan seberapa kecil suatu bank dan diukur dengan memakai aset yang dimiliki (Praja \& Hartono, 2019). Bank merupakan industri yang dalam kegiatan usahanya mengandalkan kepercayaan masyarakat. Bank dianggap sebagai tempat kepercayaan nasabah untuk mengelola dananya. Bank dengan manajemen yang baik harus bisa menjaga kepercayaan nasabah penyimpan dananya. Dalam menjaga kepercayaan nasabah, kesehatan bank harus dipelihara. Salah satu pemeliharaan kesehatan bank dilakukan dengan tetap menjaga likuiditas sehingga bank dapat memenuhi kewajibannya dan menjaga kinerjanya agar bank selalu memperoleh kepercayaan dari masyarakat. Kepercayaan masyarakat terhadap bank akan terwujud apabila bank mampu meningkatkan kinerjanya secara optimal (Lasta, 2014).

Bank yang sehat adalah bank yang dapat menjalankan fungsinya dengan baik, dengan kata lain, bank yang sehat adalah bank yang dapat menjaga dan memelihara kepercayaan masyarakat, dapat menjalankan fungsi intermediasi, dapat membantu kelancaran lalu lintas pembayaran serta dapat digunakan oleh pemerintah dalam melaksanakan berbagai kebijakannya, terutama kebijakan moneter (Permana, 2012).

Bank umum persero merupakan bagian dari bank umum yang beroperasi di Indonesia. Saat ini bank umum persero yang beroperasi yakni, Bank Mandiri, Bank Rakyat Indonesia (BRI), Bank Negara Indonesai (BNI), dan Bank Bank Tabungan Negara (BTN). Dalam pelaksanaan operasionalnya bank umum persero menjadi bagian dari Badan Usaha Milik Negara (BUMN). Undang-Undang Nomor 19 Tahun 2003 tentang BUMN menyatakan bahwa badan usaha yang seluruh atau sebagian besar modalnya dimiliki oleh negara. Kemudian dalam Pasal 1 ayat 2 dinyatakan bahwa Perusahaan Perseroan, yang selanjutnya disebut Persero, adalah BUMN yang berbentuk perseroan terbatas yang modalnya terbagi dalam saham yang manyoritas dimiliki oleh pemerintah dengan tujuan utamanya mengejar keuntungan. Oleh karena itu, mengacu 
kepada aturan perundang-undangan tersebut dinyatakan bahwa bank umum persero memiliki tujuan yakni memperoleh keuntungan, sehingga dalam pelaksanaan operasinya harus memiliki kinerja keuangan yang baik agar perusahaan tersebut memeperoleh keuntungan.

Cukup besarnya peran perbankan dalam meningkatkan kesejahteraan masyarakat serta menjadi bagian penting dalam mendorong pertumbuhan ekonomi nasional tercatat berdasarkan data Otoritas Jasa Keuangan dalam Statistik Perbankan Indonesia tahun 2018 jumlah bank umum yang beroperasi di Indonesia sebanyak 115 dengan jumlah dana yang disalurkan sebanyak

Rp. 7.667 triliun atau tumbuh sebesar 6,83\% dibandingkan pada tahun 2017. Sedangkan jumlah asset yang dimiliki sebesar Rp. 7.913 triliun tumbuh sebesar 7,12\% dibandingkan tahun 2017.

Profitabilitas adalah salah satu indikator kinerja sebuah perusahaan dalam memperoleh keuntungan. Terdapat dua faktor yang mempengaruhi kinerja profitabilitas, yakni faktor dari internal perusahaan dan faktor dari eksternal. Menurut (Athanasoglou, Brissimis, \& Delis, 2008), bahwa kinerja profitabilitas suatu bank merupakan hasil dari kinerja faktor internal dan eksternal. Kinerja keuangan sebuah perusahaan bisa ditinjau dari aspek kemampuan dan efektifitas dalam penggunaan dana dan mengelola biaya (Kartikasari \& Wahyuati, 2014).

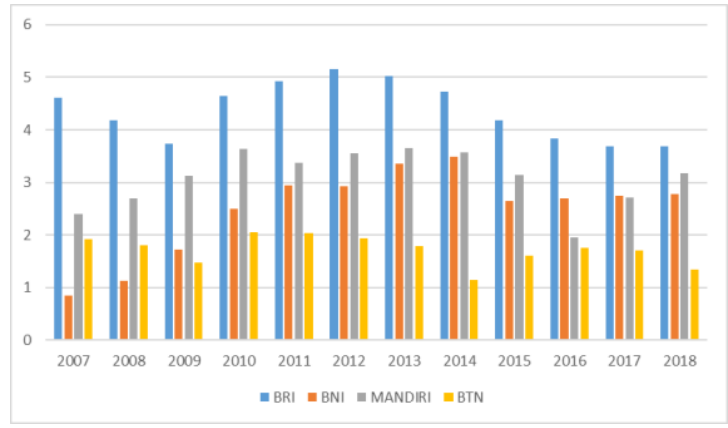

Gambar 1

Perkembangan Return on Asset (ROA) Bank Umum Persero Tahun 2007-2018 (dalam persen) Sumber : Laporan keuangan (data diolah)

Perkembangan Return on Asset (ROA) Bank Umum Persero dari tahun 2007 sampai 2018 mengalami fluktuatif namun cenderung meningkat. Peningkatan ini artinya bank dapat mengelola asetnya dengan baik untuk menghasilkan laba bersih. Sedangkan penurunan tersebut terjadi karena adanya persaingan yang cukup tinggi, suku bunga yang terus menurun, beban regulasi untuk penambahan cadangan modal dan juga kredit bermasalah yang tinggi.

Semakin tinggi nilai ROA, maka semakin baik pula kemampuan perusahaan dalam mengelola asetnya. ROA dengan nilai tertinggi yaitu Bank BRI dengan nilai Rata-rata 4,37\%. Sedangkan ROA dengan nilai Terendah yaitu Bank BTN dengan nilai 
Rata-rata $1,71 \%$. Artinya Bank BRI adalah bank yang paling baik diantara bank persero lainnya. Sedangkan Bank BTN adalah Bank yang kurang baik diantara bank persero.

Menurut (Sudiyatno, 2013) menyatakan bahwa hubungan antara Kinerja Profitabilitas dan Adequacy Ratio (CAR) memiliki hubungan positif. Sedangkan untuk indikator kredit, (Suryani, 2012) menyatakan bahwa jika dilihat dari indikator Non Performing Loan (NPL) dihubungkan dengan Profitabilitas memiliki hubungan negatif, dikarenakan semakin besar indikator NPL maka akan memberikan dampak berkurangnya profitabilitas sebuah perusahaan. Untuk indikator profitabilitas, menurut (Pratami \& Muharam, 2011), Return on Asset (ROA) menjadi salah satu indikator penting dalam operasional perbankan, karena profitabilitas perbankan yang menggunakan perbandingan dengan asset yang bersumber dari dana yang dihimpun dari Dana Pihak Ketiga (DPK), sehingga rasio ROA tersebut mencerminkan terkait kinerja internal perbankan didalam memperoleh keuntungan.

Menurut (Muhaemin \& Wiliasih, 2016) menyatakan bahwa faktor eksternal yang memberikan pengaruh terhadap indikator profitabilitas antara lain; (1) inflasi; (2) suku bunga; (3) nilai tukar; dan (4) jumlah uang beredar. Perbankan di Indonesia dalam menjalankan aktivitas usahanya diawasi oleh Bank Indonesia dan Otoritas Jasa Keuangan. Dalam melaksanakan tugas dan fungsi perbankan akan terkait langsung dengan kebijakan moneter.

Bank Indonesia dalam menjalankan kebijakan moneter menggunakan kerangka kerja inflasi atau Inflation Targeting Framework (ITF). Sehingga Bank Indonesia akan terus menjaga indikator-indikator makro yang terkait dengan stabilitas inflasi. Berdasarkan hasil penelitian yang dilakukan oleh (Dwijayanthy \& Naomi, 2009), menyatakan bahwa hubungan antara inflasi dengan profitabilitas memberikan pengaruh negatif. Untuk BI Rate tidak memberikan pengaruh yang signifikan terhadap profitabilitas, sedangkan untuk nilai tukar memberikan pengaruh negatif terhadap profitabililtas perbankan.

\section{Metode Penelitian}

Metode yang digunakan dalam penelitian ini adalah metode deskriptif dan verifikatif. Metode deskriptif digunakan untuk menggambarkan Kondisi variabel Ekonomi makro serta Perkembangan Kinerja Internal Bank Persero dan BPD Periode 2007-2018. Sedangkan Metode verifikatif digunakan untuk mengetahui hubungan antar dua variabel atau lebih yaitu untuk menjelaskan atau menganalisis bagaimana pengaruh Dana Pihak Ketiga, CAR, NPL, BI rate, Inflasi, dan Nilai tukar terhadap Profitabilitas Bank Persero dan Bank BPD Periode 2007-2018. Untuk metode estimasi model regresi dengan menggunakan data panel. Metode analisis data yang dilakukan dalam penelitian ini menggunakan metode regresi data panel atau panel pooled data. Model regresinya dapat ditulis sebagai berikut : 


$$
Y_{i t}=\beta_{0 i t}+\beta_{1 i t} X_{1 i t}+\beta_{2 i t} X_{2 i t}+\beta_{3 i t} X_{3 i t}+\beta 4 i t X 4 i t+\beta_{5 i t} X_{5 i t}+e
$$

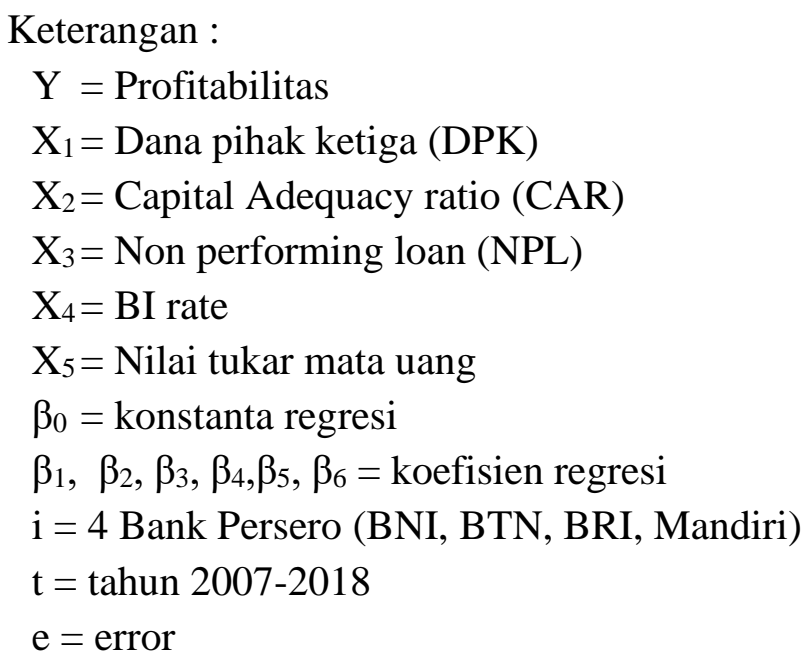

\section{Hasil dan Pembahasan}

\section{A. Hasil Penelitian}

Studi ini menggunakan data time series dan cross section. Sumber data yang digunakan, terkait data kinerja internal diperoleh dari data laporan Tahunan Bank Umum Persero. Sedangkan untuk data makro sumber data diperoleh dari publikasi Bank Indonesia dan Badan Pusat Statistika dari kurun waktu 2007-2018. Berdasarkan hasil pengolahan data menggunakan EViews 6.0 diperoleh hasil pada tabel sebagai berikut:

Tabel 1

Hasil Regresi

\begin{tabular}{ccc}
\hline Variabel & Koefisien & Probabilitas \\
\hline $\mathrm{C}$ & 19,16087 & 0,0002 \\
\hline $\log (\mathrm{DPK})$ & 0,223497 & 0,3978 \\
\hline $\mathrm{CAR}$ & 0,028614 & 0,2876 \\
\hline $\mathrm{NPL}$ & $-0,407377$ & 0,0000 \\
& & 0,0986 \\
\hline $\mathrm{BR}$ & 0,107686 & 0,0082 \\
\hline $\log (\mathrm{NT})$ & $-1,869481$ & 0,921230 \\
\hline $\mathrm{R}^{2}$ & \multicolumn{2}{c}{} \\
\hline & Sumber : Data diolah peneliti
\end{tabular}

Sehingga persamaan regresinya adalah sebagai berikut:

$Y_{i t}=19,1608+0,2234 X_{1}+0,0286 X_{2}-0,4073 X_{3}+0,1076 X_{4}-1,8694 X_{5}+e$

Hasil regresi dengan menggunakan indikator ROA sebagai variabel terikatnya sudah sesuai semua dengan tandanya. Namun ketika melihat Probabilitas nya, ada 3 variabel yang tidak signifikan, melihat dari hasil penelitian sebelumnya dan teori yang ada bahwa seharusnya Dana Pihak Ketiga, CAR, dan BI rate berpengaruh signifikan terhadap ROA. 


\section{B. Pembahasan}

Kinerja profitabilitas yang tergambar dari indikator ROA untuk Bank BRI pada tahun 2007 sampai 2018 mengalami fluktuatif namun cenderung menurun. Pada tahun 2007 berada di angka 4,61\% dan pada tahun 2018 berada di angka $3,68 \%$. Hal ini tentu tidak baik bagi bank BRI. Penurunan ROA ini biasanya disebabkan oleh Persaingan antar bank, suku bunga yang terus menurun, beban regulasi untuk penambahan modal dan juga kredit bermasalah yang tinggi. Bank BNI pada tahun 2007 sampai 2018 Mengalami naik fluktuatif namun cenderung meningkat. Pada tahun 2007 berada di angka 0,85\% dan pada tahun 2018 berada di angka 2,78\%. Hal ini tentu sangat baik bagi bank BNI. Artinya bank bisa mengelola asetnya dengan baik untuk menghasilkan laba bersih. ROA Bank Mandiri dari tahun 2007 sampai 2018 mengalami fluktuatif namun cenderung meningkat. Pada tahun 2007 berada di angka 2,40\% dan pada tahun 2018 berada di angka 3,17\%. pada tahun 2007 sampai 2018 mengalami naik turun, Namun cenderung menurun. Pada tahun 2007 ROA Bank BTN berada di angka 1,92\% dan pada tahun 2018 berada di angka 1,34\%. Penurunan tersebut terjadi karena adanya persaingan yang cukup ketat, suku bunga yang terus menurun, dan kredit bermasalah yang tinggi.

Perkembangan Dana Pihak Ketiga Bank Persero tahun 2007-2018 mengalami peningkatan dari tahun ke tahun. Semakin banyak masyarakat menabung di bank, maka semakin besar pula penyaluran kredit yang diberikan oleh bank kepada masyarakat dan dimana dalam penyaluran kredit itu bank mendapatkan laba dari bunga. Dana Pihak Ketiga tertinggi berada di Bank Mandiri dengan nilai rata-rata Rp. 534,31 triliun rupiah. Sedangkan Dana Pihak Ketiga terendah berada di Bank BTN dengan nilai rata-rata Rp.96,02 triliun rupiah. Hal ini menunjukan Bank Mandiri adalah yang paling baik diantara bank persero lainnya. Sedangkan Bank BTN adalah bank yang kurang baik diantara bank persero.

CAR adalah rasio yang memperlihatkan seberapa jauh aktiva bank yang mengandung risiko (kredit, penyertaan, surat berharga, tagihan pada bank lain) ikut dibiayai dari dana modal sendiri bank di samping memperoleh dana-dana dari sumber-sumber diluar bank, seperti dana masyarakat, pinjaman (hutang), dll. CAR tertinggi berada di Bank BTN dengan nilai rata-rata $17,83 \%$. Sedangkan CAR terendah berada di Bank BNI dengan nilai rata-rata $16,93 \%$ (Setiawan \& Indriani, 2016). Hal ini menunjukan Bank BTN adalah yang paling sehat dari segi permodalan diantara bank Persero lainnya. Sedangkan Bank BNI adalah bank yang kurang sehat diantara bank Persero berdasarkan indikator CAR.

Perkembangan NPL Bank Persero tahun 2007-2018 mengalami fluktuatif namun cenderung menurun. Semakin kecil nilai NPL maka semakin kecil resiko yang ditanggung pihak bank sehingga dapat meningkatkan profitabilitas. NPL tertinggi terjadi pada tahun 2007 yaitu Bank BNI berada di angka 8,18\%. Kondisi ini melebihi batas minimum yang telah ditetapkan yaitu 5\%. Kondisi ini 
tentu tidak baik bagi suatu bank. Pada tahun 2007 sedang ada krisis ekonomi di Amerika dan berdampak kepada negara berkembang seperti Indonesia. Ekonomi negara Indonesia saat itu sedang melamah, dan sektor perbankan pun ikut terkena imbasnya. Sedangkan NPL terendah terjadi pada tahun 2013 yaitu ada di Bank BRI. Kondisi ini menggambarkan suatu bank dalam kondisi baik. NPL bank Mandiri dari tahun 2007-2018 mengalami fluktuatif namun cenderung menurun. Pada tahun 2007 berada di angka 7,33\% dan pada tahun 2018 berada di angka 2,79\%. NPL bank BTN dari tahun 2007-2018 mengalami fluktuatif namun cenderung menurun. Pada tahun 2007 berada di angka 4,05\% dan pada tahun 2018 berada di angka 2,82\%.

Untuk indikator eksternal, BI Rate sebagai sebuah instrumen kebijakan moneter dalam bentuk suku bunga acuan, perkembangan BI dari tahun 2007 sampai 2018 mengalami fluktuatif namun cenderung menurun. Pada tahun 2007 berada di angka 8\% dan pada tahun 2018 berada di angka 6\%. BI Rate yang tinggi cenderung akan memperlambat pertumbuhan ekonomi, sedangkan BI Rate yang relatif rendah akan memberikan ruang bagi ekonomi untuk tumbuh lebih cepat. Pada tahun 2007 berada di angka 6,59\% dan pada tahun 2018 berada di angka $3,13 \%$.

Indikator lainnya adalah inflasi, perkembangan tingkat inflasi menggambarkan bahwa perekonomian indonesia berubah ke arah yang lebih baik. Pada tahun 2008 mengalami nilai yang cukup tinggi yaitu 11,06\%. Hal ini disebabkan karena terjadi krisis ekonomi di Amerika Serikat dan berdampak kepada negara berkembang seperti Indonesia. Pertumbuhan tingkat inflasi yang tidak teratur ini mengakibatkan perekonomian masyarakat menjadi tidak menentu. Hal ini mengakibatkan BI-Rate juga terpengaruh dan berpengaruh pada pembiayaan.

Indikator terakhir adalah nilai tukar, perkembangan nilai tukar dari tahun 2007 sampai 2018 mengalami fluktuatif namun cenderung meningkat. Pada tahun 2007 berada di angka Rp.9.419 dan pada tahun 2018 berada di angka Rp.14.710. Peningkatan kurs ini menggambarkan mata uang domestik nilainya turun terhadap mata uang asing. Artinya ekonomi negara Indonesia sedang melemah. Nilai tukar tertinggi sebesar Rp.14.710 terjadi pada tahun 2018. Hal ini menandakan pada saat itu Indonesia mengalami perlambatan pertumbuhan ekonomi. Sedangkan Nilai tukar terendah sebesar Rp.8.991 terjadi pada tahun 2010, Hal ini menunjukkan bahwa bagusnya perekonomian Indonesia pada saat itu.

Hasil penelitian menyatakan bahwa koefisien DPK bernilai positif sebesar 0,2234. Hasil tersebut sesuai dengan penelitian (Anggreni \& Suardhika, 2014), (Indriani, 2016) dan (Parenrengi \& Hendratni, 2018), walaupun dalam hasil penelitian ini nilai probabilitas untuk DPK sebesar 39,7\% lebih besar dari $\alpha=$ $5 \%$, sehingga DPK tidak berpengaruh signifikan terhadap ROA. Pada umumnya peningkatan DPK akan mendorong pada peningkatan laba atau profitabilitas. 
Untuk rasio kecukupan modal (CAR), menghasilkan hubungan positif terhadap ROA dengan nilai koefisien sebesar 0,0286. CAR sebagai sebuah indikator kekuatan perbankan dari sisi permodalan, akan memberikan gambaran bahwa bank tersebut dalam jangka waktu tertentu tidak membutuhkan tamabahan modal dari faktor eksternal, teruatam dalam hal ini bank umum persero, dimana mayoritas kepemilikan modalnya dimiliki oleh pemerintah. Penelitian (Dewi \& Prasetiono, 2011) menyatakan bahwa CAR perbankan memiliki hubungan positif terhadap peningkatan laba atau profitabilitas perbankan. Berdasarkan kepada ketentuan yang ditetapkan oleh Bank Indonesia, bahwa sebuah bank dikatakan sehat jika memiliki indikator CAR paling sedikit $8 \%$. Indikator tersebut memberikan indikasi bahwa bank tersebut mampu membiayai operasional dan memberikan keuntungan bagi bank tersebut.

Berbeda dengan indikator DPK dan CAR, untuk NPL, sebagai sebuah indikator kredit macet dari perbankan, dalam penelitian ini menghasilkan hubungan negatif sebesar 0,4073 terhadap profitabilitas. Hasil penelitian ini sejalan dengan (Pinasti \& Mustikawati, 2018) menyatakan hubungan negatif antara NPL dan profitabilitas, ini menandakan bahwa semakin baik operasional perbankan bisa dilihat dari strategi sebuah perbankan dalam mengelola risiko kredit macet. Permasalahan utama yang sering dihadapi oleh sektor perbankan adalah tingginya angka kredit macet. Otoritas Jasa Keuangan (OJK) telah membuat sebuah ketetapan bahwa batas maksimal NPL sebuah bank sebesar 5\% dari total kredit yang disalurkan.

Untuk variabel yang bersifat eksternal yakni BI Rate dalam penelitian ini menghasilkan nilai positif terhadap profitabilitas perbankan, hasil tersebut sejalan dengan penelitian (Ali, Shafique, Razi, \& Aslam, 2012) menyatakan bahwa tingkat bunga menghasilkan hubungan positif terhadap profitabiltas. Perkembangan tingkat bunga BI Rate menjadi sebuah acuan dalam menetapkan tingkat bunga pasar yang berlaku bagi perbankan. Penentuan tingkat bunga oleh sebuah bank bertujuan untuk melihat seberapa besar sebuah bank mampu mengelola cost of fund dari dana yang dikelolanya, sehingga suku bunga yang ditetapkan harus kompetitif, agar bisa menarik para debitur maupun kreditur untuk menjadi nasabah dan pada akhirnya berdampak kepada kinerja perbankan dalam memperoleh laba menjadi meningkat.

Variabel terakhir dalam penelitian ini adalah nilai tukar, berdasarkan kepada hasil pengolahan data, nilai tukar mengasilkan nilai negatif sebesar 1,8694. Nilai koefisien nilai tukar menjadi yang terbesar diantara variabel-variabel yang diteliti, hal ini menjadi sebuah indikasi bahwa, nilai tukar memberikan pengaruh yang cukup besar bagi sektor perbankan dalam memperoleh laba. Hal tersebut dikarenakan perbankan harus melihat bahwa transaksi-transaki yang dilakukan akan sangat sensitif terhadap perubahan nilai tukar. Hal tersebut sejalan dengan penelitian (Dwijayanthy \& Naomi, 2009), menyatakan bahwa sektor perbankan harus memiliki cadangan valuta asing terkait dengan tanggal jatuh tempo transaksi-transaksi perbankan. Jika kurs terus mengalami apresiasi maka 
perbankan akan memperoleh kinerja laba yang baik dengan menguatnya nilai tukar, dan sebaliknya jika nilai tukar melemah, maka kinerja perbankan dalam memeperoleh laba akan cukup terkoreksi.

\section{Kesimpulan}

Kinerja perbankan dalam memperoleh laba dengan ROA sebagai indikator profitabilitas, dalam penelitian ini dipengaruhi oleh faktor internal dan faktor eksternal. Untuk faktor internal penelitian ini menggunakan variabel DPK, CAR, dan NPL, sedangkan untuk variabel eksternal menggunakan variabel BI Rate dan nilai tukar. Untuk variabel yang menghasilkan hubungan negatif yakni NPL dan nilai tukar, sedangkan untuk variabel yang menghasilkan hubungan positif yakni variabel DPK, CAR dan tingkat bunga. variabel nilai tukar dan NPL, jika dilihat dari nilai koefisien menghasilkan nilai terbesar dan memberikan pengaruh yang signifikan terhadap profitabilitas. Dengan kata lain, bahwa perbankan dalam menghasilkan laba, harus melihat indikator utamanya yakni NPL dan nilai tukar. 


\section{BIBLIOGRAFI}

Ali, Syed Atif, Shafique, Azam, Razi, Amir, \& Aslam, Umair. (2012). Determinants of profitability of Islamic banks, A case study of Pakistan. Interdisciplinary Journal of Contemporary Research in Business, 3(11), 86-99.Google Scholar

Anggreni, Made, \& Suardhika, Made. (2014). Pengaruh Dana Pihak Ketiga, Kecukupan Modal, Risiko Kredit Dan Suku Bunga Kredit Terhadap Profitabilitas Bank Bumn Tahun 2010-2012. E-Jurnal Akuntansi, 9(1), 27-37. Google Scholar

Athanasoglou, Panayiotis P., Brissimis, Sophocles N., \& Delis, Matthaios D. (2008). Bank-specific, industry-specific and macroeconomic determinants of bank profitability. Journal of International Financial Markets, Institutions and Money, 18(2), 121-136. Google Scholar

Dewi, Dhika Rahma, \& PRASETIONO, Prasetiono. (2011). Faktor-faktor yang mempengaruhi profitabilitas bank syariah di Indonesia. Universitas Diponegoro. Google Scholar

Dwijayanthy, Febrina, \& Naomi, Prima. (2009). Analisis Pengaruh Inflasi, BI Rate, dan Nilai Tukar Mata Uang terhadap Profitabilitas Bank Periode 2003-2007 [English: Analysis of Effect of Inflation, BI Rate, and Exchange Rate on Bank Profitability (Period 2003-2007)]. Jurnal Karisma, 3(2), 87-98. Google Scholar

Indriani, Fitri. (2016). Kompetensi pedagogik mahasiswa dalam mengelola pembelajaran tematik integratif kurikulum 2013 pada pengajaran micro di pgsd uad Yogyakarta. Elementary School: Jurnal Pendidikan Dan Pembelajaran Ke$S D-A n, 3(1)$. Google Scholar

Kartikasari, Meidita, \& Wahyuati, Aniuek. (2014). Penilaian kinerja keuangan menggunakan analisis rasio pada bank mandiri di BEI. Jurnal Ilmu \& Riset Manajemen, Sekolah Tinggi Ilmu Ekonomi Indonesia (STIESIA), 3(11). Google Scholar

Lasta, Heidy Arrvida. (2014). Analisis tingkat kesehatan bank dengan menggunakan pendekatan RGEC (risk profile, good corporate governance, earnings, capital)(studi pada PT Bank Rakyat Indonesia, tbk periode 2011-2013). Jurnal Administrasi Bisnis, 13(2).

Muhaemin, Ahmad, \& Wiliasih, Ranti. (2016). Analisis Faktor-Faktor Yang Memengaruhi Profitabilitas Bank Pembiayaan Rakyat Syariah Di Indonesia. Nisbah: Jurnal Perbankan Syariah, 2(1), 180-206. Google Scholar

Parenrengi, Sudarmin, \& Hendratni, Tyahya Whisnu. (2018). Pengaruh dana pihak ketiga, kecukupan modal dan penyaluran kredit terhadap profitabilitas bank. Jurnal Manajemen Strategi Dan Aplikasi Bisnis, 1(1), 9-18. Google Scholar

Permana, Bayu Aji A. J. I. (2012). Analisis Tingkat Kesehatan Bank Berdasarkan Metode Camels dan Metode RGEC. Jurnal Akuntansi Akunesa, 1(1). Google 
Scholar

Pinasti, Wildan Farhat, \& Mustikawati, R. R. Indah. (2018). Pengaruh CAR, BOPO, NPL, NIM Dan LDR Terhadap Profitabilitas Bank Umum Periode 2011-2015. Nominal: Barometer Riset Akuntansi Dan Manajemen, 7(1), 126-142. Google Scholar

Praja, Nasya Batari Ayunda, \& Hartono, Ulil. (2019). Pengaruh Ukuran Perusahaan, Capital Adequacy Ratio (Car), Loan To Deposit Ratio (Ldr), Non Performing Loan (Npl) Terhadap Profitabilitas Pada Bank Umum Swasta Nasional Devisa Yang Terdaftar Di Indonesia Periode 2012-2016. Jurnal Ilmu Manajemen (JIM), 7(1). Google Scholar

Pratami, Wuri Arianti Novi, \& Muharam, Harjum. (2011). Analisis Pengaruh Dana Pihak Ketiga (Dpk), Capital Adequacy Ratio (Car), Non Performing Financing (Npf) Dan Return On Asset (Roa) Terhadap Pembiayaan Pada Perbankan Syariah (Studi Kasus Pada Bank Muamalat Indonesia Periode 2001-2011). Universitas Diponegoro.

Setiawan, Ulin Nuha Aji, \& Indriani, Astiwi. (2016). Pengaruh Dana Pihak Ketiga (DPK), Capital Adequacy Ratio (CAR), dan Non Performing Financing (NPF) terhadap Profitabilitas Bank Syariah dengan Pembiayaan sebagai Variabel Intervening. Diponegoro Journal of Management, 5(4), 121-131.

Sudiyatno, Bambang. (2013). Pengaruh risiko kredit dan efisiensi operasional terhadap kinerja bank (Studi Empirik pada bank yang terdaftar di Bursa Efek Indonesia). Jurnal Organisasi Dan Manajemen, 9(1), 73-86. Google Scholar

Suryani, Suryani. (2012). Analisis Pengaruh Financing To Deposit Ratio (Fdr) Terhadap Profitabilitas Perbankansyariah Di Indonesia (Rasio Keuangan pada BUS dan UUS Periode 2008-2010). Economica: Jurnal Ekonomi Islam, 2(2), 153-170. Google Scholar

\section{Copyright holder :}

Gugum Mukdas Sudarjah, Sidik Priadana, Reza Anugrah Pratama (2021)

First publication right :

Jurnal Syntax Idea

This article is licensed under:

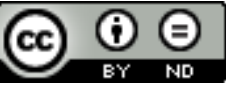

